\title{
UPAYA PENINGKATAN HASIL BELAJAR BIOLOGI SISWA KELAS X MENGGUNAKAN MODEL PEMBELAJARAN STUDENT ACILITATOR AND EXPLAINING
}

\author{
Merti Triyanti ${ }^{1}$, Usman Nulhakim2 \\ STKIP PGRI Lubuklinggau ${ }^{1}$, SMA Negeri 7 Lubuklinggau ${ }^{2}$ \\ merti@stkippgri-lubuklinggau.ac.id ${ }^{1}$
}

\begin{abstract}
ABSTRAK
Tujuan penelitian ini adalah untuk mengetahui peningkatan hasil belajar biologi siswa kelas X SMA negeri 7 Lubuklinggau dengan menerapkan model pembelajaran student facilitator and explaining. Penelitian ini merupakan Penelitian Tindakan Kelas (PTK) yakni penelitian yang terdiri dari 2 siklus dimana tiap siklus terdiri dari empat langkah yaitu : perencanaan, pelaksanaan, pengamatan, dan refleksi. Pengumpulan data dilakukan dengan lembar observasi kegiatan guru dan lembar tes ulangan harian. Subjek penelitian ini adalah siswa kelas X SMA Negeri 7 Lubuklinggau sebanyak 38 siswa. Dari hasil penelitian diketahui bahwa dengan menerapkan model pembelajaran student facilitator and explaining, siswa yang mencapai KKM dari 52,88\% pada siklus I menjadi 86,21\% pada siklus II. Berdasarkan analisa data tersebut dapat disimpulkan bahwa dengan menerapkan model pembelajaran student facilitator and explaining kualitas pembelajaran pada mata pelajaran Biologi di kelas X SMA Negeri 7 Lubuklinggau meningkat. Adapun besar peningkatan hasil belajar siswa kelas $\mathrm{X}$ SMA Negeri 7 Lubuklinggau pada pembelajaran biologi menggunakan model pembelajaran student facilitator and explaining sebesar 33,33\%. Simpulan, terjadi peningkatan hasil belajar biologi siswa kelas X SMA Negeri 7 Lubuklinggau dengan menerapkan model pembelajaran student facilitator and explaining.
\end{abstract}

Katakunci: hasil belajar biologi, student facilitator and explaining

\begin{abstract}
The purpose of this study was to determine the improvement in biology learning outcomes of class X students of SMA 7 Lubuklinggau by applying the student facilitator and explaining learning model. This research is Classroom Action Research (CAR), which is a study consisting of 2 cycles where each cycle consists of four steps: planning, implementing, observing, and reflecting. Data collection was carried out with the teacher activity observation sheet and the daily test sheet. The subjects of this study were 38 students of class X in SMA Negeri 7 Lubuklinggau. From the research results it is known that by applying the student facilitator and explaining learning model, students who reach KKM from $52.88 \%$ in the first cycle to $86.21 \%$ in the second cycle. Based on the analysis of these data it can be concluded that by applying the learning facilitator and explaining learning model the quality of learning in Biology subjects in class X SMA Negeri 7 Lubuklinggau increases. The magnitude of the increase in student learning outcomes in class X SMA Negeri 7 Lubuklinggau on biology learning using the student facilitator and explaining learning model by 33.33\%. Conclusion, an
\end{abstract}


increase in biology learning outcomes of class $X$ students of SMA Negeri 7 Lubuklinggau by applying the student facilitator and explaining learning model.

Keywords: biology learning outcomes, student facilitator and explaining

\section{PENDAHULUAN}

Pendidikan merupakan hal yang paling mendasar yang tidak bisa lepas dari kehidupan semua orang. Pendidikan yang baik akan menghasilkan sumber daya manusia yang baik karena pendidikan adalah kunci semua kemajuan dan perkembangan yang berkualitas. Pendidikan berlangsung dalam segala lingkungan, baik yang khusus diciptakan untuk kepentingan kependidikan maupun yang ada dengan sendirinya. Oleh karena itu dalam menciptakan suatu pendidikan yang bermutu perlu mendapatkan penanganan yang lebih baik, karena dengan adanya pendidikan akan menentukan peradaban manusia pada manusia yang akan datang (Kadir, 2012).

Menurut Fitri (2010) kebanyakan dalam pendidikan untuk proses pembelajaran, peserta didik kurang didorong untuk mengembangkan kemampuan berpikirnya. Proses pembelajaran di dalam kelas biasanya hanya diarahkan kepada kemampuan peserta didik menghapal informasi yang disampaikan oleh seorang pendidik. Itu menyebabkan peserta didik hanya bisa untuk menerima informasi di dalam otaknya saja, tanpa ada memikirkan bagaimana cara agar bisa memecahkan permasalahan yang ada. Keterampilan yang dimiliki peserta didik merupakan hasil dari proses belajar dan untuk mendapatkan hasil yang maksimal, peserta didik harus dilatih dalam berbagai aspek tingkah laku (Slameto, 2010).

Biologi sebagai salah satu rumpun sains merupakan pondasi dari ilmu pengetahuan dan teknologi. Biologi adalah ilmu pengetahuan yang mempelajari gejala-gejala alam dan interaksi didalamnya, yang menekankan pada pemberian pengalaman langsung untuk mengembangkan kemampuan guru agar mampu mengembangkan suatu strategi dalam mengajar yang dapat meningkatkan motivasi siswa, sehingga keaktifan siswa dalam mengikuti kegiatan belajar mengajar meningkat.

Oleh karena itu perlu kematangan dalam proses mempelajari biologi sehingga dihasilkan seorang ahli yang berkompeten. Septianing (2013) menyatakan bahwa istilah biologi berasal dari bahasa yunani yaitu bios kehidupan dan logos pengetahuan, artinya ilmu tersebut mencakup kajian tentang mahkluk hidup, baik hewan maupun tumbuhan. Dalam pembelajaran biologi menuntun siswa untuk mengikuti proses pembelajaran secara aktif serta terlibat dalam pembelajaran yang dirancang oleh guru agar tujuan pembelajaran dapat di capai dengan baik.

Cara mengajar dikatakan efektif jika mencapai tujuan yang diharapkan (Trianto, 2009). Untuk mencapai hal tersebut, maka perlu dilakukan inovasi dalam proses pembelajaran, seperti penggunaan model pembelajaran kooperatif. Salah satu model pembelajaran kooperatif yang dapat digunakan adalah model 
pembelajaran Student Facilitator and Expaining. Menurut Kurniasih (2015) salah satu kelebihan model pembelajaran Student Facilitator and Expaining adalah dalam proses pembelajaran siswa diajak untuk dapat menjelaskan materi pelajaran kepada siswa lain yang dapat meningkatkan keaktifan siswa adalah model pembelajaran kooperatif.

Berdasarkan hasil observasi dengan salah satu guru biologi kelas $\mathrm{X}$, di SMA Negeri 7 Lubuklinggau kegiatan belajar mengajar belum banyak menggunakan model-model pembelajaran yang dilaksanakan oleh guru, termasuk model pembelajaran kooperatif student acilitator and explaining. Hal ini akan mendukung terlaksananya penelitian tindakan kelas yang akan dilaksanakan dan dapat menjadi referensi bagi guru untuk meningkatkan hasil belajar biologi siswa. Selain itu, model pembelajaran student acilitator and explaining dapat melatih siswa untuk mampu berbicara di depan orang lain, melatih daya ingat dan pemahaman siswa serta menjalin komunikasi yang efektif antar siswa. Tujuan penelitian ini adalah untuk mengetahui peningkatan hasil belajar biologi siswa kelas X SMA negeri 7 Lubuklinggau dengan menerapkan model pembelajaran student facilitator and explaining.

\section{METODE PENELITIAN}

Penelitian ini merupakan Penelitian Tindakan Kelas (PTK). yang terdiri dari 2 siklus dimana tiap siklus terdiri dari empat langkah yaitu : perencanaan, pelaksanaan, pengamatan, dan refleksi. Peningkatan kualitas pembelajaran biologi melalui model pembelajaran student acilitator and explaining. Subjek penelitian dalam penelitian tindakan kelas ini adalah siswa yaitu mengamati hasil belajar dalam proses pembelajaran, sampel siswa yang digunakan yaitu sebanyak 38 siswa. Guru, yaitu kemampuan dan keterampilan guru dalam menggunakan model student acilitator and explaining dalam pembelajaran.

Data observasi guru digunakan untuk merefleksi siklus yang telah dilakukan dan diolah secara deskriptif. Tingkat observasi guru meliputi dua komponen yaitu data observasi rencana pelaksanaan pembelajaran dan data observasi pelaksanaan pembelajaran. Skor pengamtan lembar observasi RPP dan pelaksanaan pembelajaran dapat dilihat pada tabel 1 berikut ini.

Tabel 1. Skor Pengamatan Lembar Observasi RPP dan Pelaksanaan Pembelajaran

\begin{tabular}{clc}
\hline No & Kriteria & Skor \\
\hline 1. & Sangat tidak baik & 1 \\
\hline 2. & Tidak baik & 2 \\
\hline 3. & Kurang baik & 3 \\
\hline 4. & Baik & 4 \\
\hline 5. & Sangat baik & 5 \\
\hline
\end{tabular}


Penentuan interval kriteria penilaian RPP dapat dilihat pada tabel 2 berikut ini.

Tabel 2. Interval Kriteria Penilaian RPP

\begin{tabular}{ccc}
\hline No & Interval & Kriteria \\
\hline 1. & $8-14$ & Sangat tidak baik \\
\hline 2. & $15-21$ & Tidak baik \\
\hline 3. & $22-28$ & Kurang baik \\
\hline 4. & $29-35$ & Baik \\
\hline 5. & $36-40$ & Sangat baik \\
\hline
\end{tabular}

Penentuan interval kriteria pelaksanaan pembelajaran tersebut dapat dilihat pada tabel 3 di bawah ini.

Tabel 3 Interval Kriteria Pelaksanaan Pembelajaran

\begin{tabular}{ccc}
\hline No & Interval & Kriteria \\
\hline 1. & $24-42$ & Sangat tidak baik \\
\hline 2. & $43-61$ & Tidak baik \\
\hline 3. & $62-80$ & Kurang baik \\
\hline 4. & $81-99$ & Baik \\
\hline 5. & $100-120$ & Sangat baik \\
\hline
\end{tabular}

Sedangkan untuk mengetahui peningkatan pada setiap pengambilan data tes, dimulai dari tes pratindakan hingga akhir siklus penelitian, menggunakan rumus berikut :

$$
X=\frac{R 2-R 1}{R 1} \times 100 \%
$$

Keterangan :

$\mathrm{X}$ : Persentase peningkatan hasil tindakan

R1 : Nilai rata-rata sebelum pratindakan

R2 : Nilai rata-rata Siklus I dan II

Untuk mengetahui ketuntasan hasil belajar siswa secara klasikal, peneliti mempresentasekan jumlah siswa yang mendapat nilai 68 ke atas mencapai $85 \%$ yaitu dengan mengubah rumus presentase sebagai berikut :

KetuntasanKlasikal $=\frac{\text { Jumlah siswa tuntas }}{\text { jumlah } \operatorname{siswa}} \times 100 \% \quad$ (Arikunto, 2006) 


\section{HASIL PENELITIAN}

Penelitian ini merupakan penelitian tindakan kelas (PTK) dengan menggunakan 2 siklus. Pada siklus II terjadi peningkatan dibandingkan siklus I baik dari hasil observasi RPP maupun Pelaksanaan pembelajaran. Data perkembangan kegiatan guru tiap siklus dapat dilihat pada tabel 4.

Tabel 4. Data Perkembangan Kegiatan Guru Tiap Siklus

\begin{tabular}{cccccc}
\hline \multirow{2}{*}{ No } & \multirow{2}{*}{ Pelaksanaan } & \multicolumn{2}{c}{ RPP } & \multicolumn{2}{c}{ Pelaksanaan Pembelajaran } \\
\cline { 3 - 6 } & & Skor & Predikat & Skor & Predikat \\
\hline 1 & Siklus I & 31 & Baik & 99 & Baik \\
\hline 2 & Siklus II & 34 & Sangat baik & 109 & Sangat baik \\
\hline
\end{tabular}

Hasil belajar siswa siklus I, jumlah siswa yang tidak mencapai KKM atau mendapatkan nilai $<75$ (belum tuntas) sebanyak 34 siswa (100\%). Artinya, pada siklus I belum ada siswa yang mencapai predikat tuntas. Hal ini dapat disebabkan kelemahan dari model pembelajaran student facilitator and explaining, yaitu adanya pendapat yang sama antara siswa satu dengan siswa lain sehingga hanya sebagian saja yang tampil (Kurniasih, 2015). Data hasil belajar siswa siklus I dapat dilihat pada tabel 5 .

Tabel 5. Hasil Belajar Siswa Siklus I

\begin{tabular}{|c|c|c|c|c|}
\hline No & Nilai & Predikat & Jumlah Siswa & Presentase (\%) \\
\hline 1 & $<75$ & Belum tuntas & 34 & 100 \\
\hline 2 & $>75$ & Tuntas & 0 & 0 \\
\hline \multicolumn{3}{|c|}{ Jumlah } & 34 & 100 \\
\hline
\end{tabular}

Hasil belajar siswa siklus II, jumlah siswa yang tidak mencapai KKM atau nilai $<75$ (belum tuntas) sebanyak 4 siswa $(14,29 \%)$. Artinya, pada siklus II ada 30 siswa yang telah mencapai predikat tuntas. Hal ini menunjukkan adanaya peningkatan hasil belajar siswa pada siklus II. Data hasil belajar siswa siklus II dapat dilihat pada tabel 6 berikut ini.

Tabel 6. Hasil Belajar Siswa Siklus II

\begin{tabular}{|c|c|c|c|c|}
\hline No & Nilai & Predikat & Jumlah Siswa & Presentase (\%) \\
\hline 1 & $<75$ & Belum tuntas & 4 & 14,29 \\
\hline 2 & $>75$ & Tuntas & 30 & 85,71 \\
\hline \multicolumn{3}{|c|}{ Jumlah } & 34 & 100 \\
\hline
\end{tabular}




\section{PEMBAHASAN}

Hasil observasi Rencana Pelaksanaan Pembelajaran yang dibuat oleh guru pada siklus pertama sudah baik yaitu dengan perolehan skor 31 dengan kriteria baik dari total skor 40. Sedangkan hasil observasi Rencana Pelaksanaan Pembelajaran yang dibuat oleh guru pada siklus kedua mengalami peningkatan menjadi 34 dari total skor 40 .

Tabel 4 menunjukkan bahwa hasil observasi RPP yang dibuat oleh guru pada siklus I sudah baik yaitu dengan perolehan skor 31 dari total skor 40, walaupun demikian masih ada kekurangan yaitu skenario pembelajaran masih kurang tergambar dengan jelas, materi pembelajaran tidak dibuat ringkasan dan hasil observasi pelaksanaan pembelajaran yang dilakukan oleh guru masih kurang yaitu dengan perolehan skor 99 dengan kriteria kurang baik dari total skor 120 . Hal ini disebabkan karena guru belum terbiasa melaksanakan pembelajaran dengan student acilitator and explaining, dan guru kurang dalam pelaksanaan proses pembelajaran, penguasaan materi pembelajaran kurang memacu dan memelihara keterlibatan siswa, kurang dalam pemanfaatan media pembelajaran, serta penggunaan bahasa yang kurang baik.

Pada siklus II hasil observasi RPP yang dibuat oleh guru mengalami peningkatan dari siklus I dengan skor 31 dari total skor 40 menjadi 34 pada siklus II dengan kriteria baik. Demikian juga untuk hasil observasi pelaksanaan pembelajaran oleh guru mengalami peningkatan dengan perolehan skor 99 dengan kriteria baik. Pada siklus II ini guru dapat mempertahankan dan meningkatkan suasana pembelajaran yang mengarah pada pembelajaran student acilitator and explaining, guru intensif membimbing siswa yang mengalami kesulitan, guru sudah baik dalam hal pelaksanaan pra pembelajaran, penguasaan materi, memacu dan memelihara keterlibatan siswa, baik dalam pemanfaatan media pembelajaran. Sedangkan tabel 5 menunjukkan hasil belajar biologi siswa kelas X. Pada siklus 1, belum ada siswa yang mencapai KKM (100\%) tidak tuntas, dengan nilai rata-rata adalah 52,88.

Hal ini dapat disebabkan kelemahan guru dalam proses pembelajaran yaitu guru belum terbiasa menciptakan suasana pembelajaran yang mengarah kepada pembelajaran student acilitator and explaining, dan siswa belum terbiasa melaksanakan pembelajaran student acilitator and explaining. Untuk siklus II diperoleh nilai rata-rata 86,21 dan siswa yang mencapai KKM 30 siswa dari 34 siswa atau $85,71 \%$.

Tercapainya target yang ditetapkan pada siklus II ini karena siswa terlihat lebih antusias dalam mengikuti proses pembelajaran. Atas dasar keberhasilan tersebut, peneliti memandang proses perbaikan pembelajaran dinyatakan sudah selesai, berhenti pada siklus II selanjutkan data tersebut peneliti gunakan guna penyusunan laporan. Karena indikator keberhasilan penelitian ini adalah sebagian siswa (85\%) mendapat nilai sama dengan atau di atas KKM yaitu 75. Keberhasilan ini sesuai dengan kelebihan model pembelajaran Student Facilitator 
and Explaining menurut Kurniasih (2015) siswa dapat menjelaskan materi pelajaran kepada siswa lainnya.

Pendapat lain dikemukakan oleh Lestari (2014) yang menyatakan bahwa kelebihan model Student Facilitator and Explaining adalah siswa dapat mengeluarkan ide-ide yang ada dipikirannya sehingga dapat memahami materi tersebut, materi yang disampaikan lebih jelas dan konkrit, dan dapat meningkatkan daya serap siswa karena pembelajaran dilakukan dengan demonstrasi. Penelitian ini sejalan dengan penelitian Irlinawati (2013), dengan judul "Penerapan Model Pembelajaran Student Facilitator and Explaining pada Perkalian Bilangan Bulat" yang menyimpulkan bahwa model pembelajaran student facilitator and explaining dapat meningkatkan prestasi belajar peserta didik.

Pada siklus I belum menunjukkan hasil yang optimal dalam meningkatkan prestasi belajar, oleh karena itu dilakukan siklus II. Prestasi belajar siswa selama pembelajaran mengalami peningkatan. Pada siklus I ketuntasan klasikal 32,56\% dengan nilai rata-rata kelas 65,03. Sedangkan pada siklus II ketuntasan klasikal $81,4 \%$ dengan nilai rata-rata kelas 76,2. Aktivitas siswa selama pembelajaran mengalami peningkatan setiap siklusnya dari 67,43\% pada siklus pertama, menjadi $82,02 \%$ pada siklus kedua. Selain itu, penelitian yang telah dilakukan oleh Hidayanti (2016) dengan judul pengaruh model pembelajaran student facilitator and explaining terhadap hasil belajar biologi siswa kelas X SMA Negeri Tugumulyo juga menunjukkan bahwa ada pengaruh model pembelajaran Student Facilitator and Explaining terhadap hasil belajar biologi siswa kelas X SMA Negeri Tugumulyo. Rata-rata nilai post-test kelas eksperimen 75,87 sedangkan kelas kontrol 58,91.

Hambatan yang ditemui saat proses pembelajaran adalah siswa lebih banyak berbicara dengan teman sebangkunya, siswa kurang aktif saat proses pembelajaran. Untuk mengatasi hal tersebut, peneliti melakukan kegiatan pembelajaran yang mampu menumbuhkan motivasi siswa agar lebih giat lagi dalam mengikuti proses pembelajaran yang telah dirancang oleh guru. Selain itu, siswa masih terlihat malu ketika menjelaskan materi didepan kelas dan menanggapi pertanyaan-pertanyaan siswa lainnya. Beberapa siswa terlihat bingung saat menjelaskan materi tersebut. Hal ini diatasi dengan memberikan arahan serta motivasi kepada siswa agar dapat menyampaikan pendapat mereka serta siswa tidak perlu malu saat menyampaikan materi dengan temannya. Model Pembelajaran Student Facilitator and Explaining diharapkan dapat menjadi salah satu model pembelajaran yang digunakan agar siswa mampu mengeluarkan ideide atau pendapat siswa terhadap suatu permasalahan atau materi pelajaran.

Hasil analisis data penelitian ini menunjukkan adanya peningkatan nilai rata-rata hasil belajar biologi siswa kelas $X$ pada siklus 1 yaitu 52,88 sedangkan pada siklus II mengalami peningkatan menjadi 86,21, yang berarti hasil belajar biologi siswa kelas X mengalami peningkatan sebesar 33,33\%. 


\section{SIMPULAN}

Berdasarkan hasil penelitian yang telah dilakukan dapat disimpulkan bahwa model pembelajaran student acilitator and explaining dapat meningkatkan hasil belajar biologi siswa Kelas X SMA Negeri 7 lubuklinggau. Hal ini dapat dilihat dari adanya peningkatan nilai rata-rata hasil belajar siswa pada siklus 1 dan siklus II. Hasil belajar biologi siswa kelas $\mathrm{X}$ mengalami peningkatan sebesar $33,33 \%$. Telah terbuktinya dengan menggunakan model pembelajaran student acilitator and explaining dapat meningkatkan kualitas pembelajaran dengan meningkatnya hasil belajar Biologi siswa kelas X. 


\section{DAFTAR PUSTAKA}

Arikunto, S. (2006). Prosedur Penelitian Suatu Pendekatan Praktik. PT Rineka Cipta. Jakarta.

Fitri. (2010). Penerapan Strategi Peningkatan Kemampuan Berpikir Siswa (SPPKB) untuk Meningkatkan Hasil Belajar Matematika Siswa Kelas IVA SD Negeri 003 Tampan Pekanbaru. (online). (http://digilib.uir.ac.id/dmdocuments/mtk,fitri.pdf). Skripsi diterbitkan. Pekanbaru: Universitas Islam Riau (di akses 12 Januari 2018)

Hidayanti, W. (2016). Pengaruh Model Pembelajaran Student Facilitator and Explaining Terhadap Hasil Belajar Biologi Siswa Kelas X SMA Negeri Tugumulyo. STKIP PGRI Lubuklinggau, Lubuklinggau.

Irlinawati, D. (2013). Penerapan Model Pembelajaran Student facilitator And Expalining Pada Perkalian Bilangan Bulat. [online] http://lppm.stkippgrisidoarjo.ac.id/files/Penerapan-ModelPembelajaranStudent-Facilitator-And-Explaining--Pada-Perkalian-BilanganBulat.pdf (diakses 20 Juli 2017)

Kadir, A. (2012). Dasar-dasar Pendidikan. Kencana. Jakarta.

Kurniasih, I. (2015). Ragam Pengembangan Model Pembelajaran Untuk Peningkatan Profesionalitas Guru. Kata Pena. Yogyakarta.

Lestari, I. (2014). Pengaruh Model Pembelajaran Student Facilitator and Expalining Terhadap Hasil Belajar IPA Kelas V. http://download.portalgaruda.org/article.php?article=138771\&val=1342 (diakses 02 Januari 2018)

Septianing, R. (2013). Panduan Belajar Biologi. Yudhistira. Jakarta.

Slameto. (2010). Belajar dan Faktor-faktor yang Mempengaruhi. Rineka Cipta. Jakarta.

Trianto. (2009). Mendesain Model Pembelajaran Inovatif Progresif. Kencana Prenada Media Group. Surabaya. 